\title{
(2) \\ Documentos, Quipus, clases e indios. Andrés Radamés Altieri en el Instituto de Antropología de la Universidad Nacional de Tucumán
}

RMA

Dossier
Sergio Carrizo

Instituto de Arqueología y Museo y Facultad de Filosofía y Letras, Universidad Nacional de Tucumán. E-mail: sercarrizo@hotmail.com

\begin{abstract}
Resumen
En 1938, tras el retiro de Alfred Métraux de la dirección del Instituto de Etnología de la Universidad Nacional de Tucumán, el campo antropológico en esta provincia fue conducido por el especialista en lenguas, Radamés Altieri (1903-1942). Su gestión académica fue breve, ya que se extendió entre 1938 y 1942. No obtuvo ningún título académico, pero impartió clases de Etnografía y Prehistoria. Publicó e investigó concentrándose en dos campos particulares: el estudio de las colecciones reunidas para el museo del instituto y la reedición de obras descriptivas de siglos pasados sobre los aborígenes del noroeste y el chaco argentino. Sostuvo el empleo de fuentes etnohistóricas para la interpretación de los contextos arqueológicos y como apoyo en el estudio de lenguas extintas. Su corta pero prolifera experiencia investigativa, lo posicionó en el ámbito del Instituto de Etnología y del Departamento de Investigaciones Regionales de la Universidad de Tucumán. A través de sus producciones logró ingresar a los círculos académicos más relevantes del país y del exterior, constituyéndose en referente fundamental sobre algunas temáticas, como el estudio de los quipus peruanos. Este artículo analiza la trayectoria académica de Altieri y contextualiza los elementos intervinientes en la configuración de su reconocimiento académico.
\end{abstract}

Palabras Claves: Radamés Altieri; Tucumán/Argentina; Etnología; Lingüística; Quipus

Documents, Quipus, classes and Indians. Andrés Radamés Altieri at the Institute of Anthropology (Universidad Nacional de Tucumán)

\begin{abstract}
Once Alfred Métraux left the Institute of Ethnology at the University of Tucumán's University in 1938, a new character took the lead of the Tucumano anthropological field. Radamés Altieri (1903-1942) was an expert in extinct languages. His academic administration lasted from 1938 until 1942. Although he had no academic degrees, he taught Ethnography and Prehistory. His publications and research revolve around two issues: the collections of the Museum and the re-publication of articles already published which dealt with the Argentine Northwest and Chaco Indians. He used ethnohistorical sources both to provide interpretations of archaeological contexts and as auxiliary sources of the study of extinct languages. His short but fruitful research experience gave him entrance to the ethnological and regional field of research at the University of Tucumán. Thus he managed to enter the academic circles in Argentina and abroad. He also became a reference on some topics, namely on Peruvian quipus. This paper analyzes Altieri's academic life and provides a context for his academic acknowledgement.
\end{abstract}

Keywords: Radamés Altieri; Tucumán/Argentina; Etnology; Linguistics; Quipus

Como sucedió en otras academias, el campo antropológico en la Argentina se constituyó en las primeras décadas del siglo $X X$ con la interacción entre aficionados $y$ especialistas ${ }^{1}$. Disputando o combinándose en un mismo

\footnotetext{
1 Más allá de las etiquetas y nominaciones, existen definiciones que marcan la presencia de los sujetos en el juego de los campos académicos. Federico Neiburg y Mariano Plotkin (2004) proponen los términos de intelectuales y expertos, como expresiones visibles de aquellos sujetos. Los intelectuales provienen de una coyuntura histórica y un espacio nacional particular. Poseen una formación general que puede o no contener estudios universitarios. Por su parte, el experto tiene exclusivamente una especialización y entrenamiento académico. Es además resultado de una trayectoria histórica más corta, ya que éstos surgieron luego de la Segunda Guerra Mundial en Estados Unidos, y se encuentran trabajando como técnicos o especialistas en aparatos del estado y OMG. Estos autores buscaron los espacios
}

espacio institucional y semántico, el reconocimiento de aquéllos que carecían de credenciales profesionales, fue decisivo no sólo en el proceso de profesionalización de la antropología sino también para definir la labor de quienes hacían de la antropología una empresa romántica, y sumarla o diferenciarla de aquéllos que aspiraban a una legitimidad científica.

Así, la definición de una disciplina de cara a la institución

de intersección productiva generados por las relaciones vinculantes entre ambos tipos. Entienden que existen pasajes y circulaciones entre las figuras de los intelectuales y de los expertos. Ideas, modelos institucionales y formas de intervención creados por intelectuales y expertos fueron jalonando la producción de conocimiento hasta la actualidad. 
que la cobijaba, y la calificación de quienes llevaban a cabo las labores que esa disciplina comprendía, eran parte de un mismo movimiento habitado por personas con mayor prestigio y distintas credenciales. A ello se agrega el tipo de calificación que demandaba cada institución, la mayoría de las veces de carácter universitario y académico. El reconocimiento entre pares o entre personas con calificaciones y trayectorias distintas, se ponía en juego a través de saberes diferenciados, y no sólo de los lugares institucionales que cada quien ocupaba. El reconocimiento, en suma, aparece en instancias de validación que llevan a visibilizar a otros que "recién llegaban", que no habían participado de labores previas en el mismo campo, ni de sus reuniones ni de sus publicaciones colectivas. ¿Por qué algunos podían ingresar a los selectos círculos de la academia, mientras otros permanecían fuera?

En este artículo analizo el "reconocimiento" como parte de la lógica de producción de conocimientos disciplinares, en el caso de Andrés Radamés Altieri, nacido en Buenos Aires en 1903. Impedido de cursar regularmente sus estudios secundarios por problemas de salud, optó por prepararse en forma privada y asistemática en el manejo de diversas lenguas modernas, así como también en latín y griego (Califano et.al. 1985: 23; Tartusi 2000). Las influencias del médico Ramón Pardal y del antropólogo italiano radicado a comienzos del siglo XX en Buenos Aires, José Imbelloni, definieron su orientación por las ciencias antropológicas ${ }^{2}$. Trabajó como colaborador de la sección antropológica del Museo Argentino de Ciencias Naturales Bernardino Rivadavia, que dirigía Imbelloni, traduciendo obras de cronistas y recopilando material que integraría al conocimiento del incario. Posteriormente en 1938 fue incorporado como secretario, luego como investigador y docente en el Instituto de Antropología de la Universidad Nacional de Tucumán, actividades que desempeñó hasta su fallecimiento súbito en 1942.

Altieri, sin titulación alguna, construyó validación empírica y operativa diseñando un objeto de estudio en torno a los documentos etnohistóricos y los quipus. El caudal de información generado contribuyó a visibilizar temáticas sobre cuestiones del pasado prehispánico americano. Pero además este programa investigativo sirvió como la base de acreditación y reconocimiento que le permitió a Altieri su ingreso al campo antropológico profesional. La antropología practicada desde la Argentina podía contribuir aportando elementos de diagnóstico al cuerpo de conocimientos del nodo andino.

En este trabajo busco dar cuenta de los elementos

\footnotetext{
2 Ramón Pardal (1896-1955) nació en Buenos Aires, fue el primer presidente de la Sociedad Argentina de Historia de la Medicina. En 1937 publicó Medicina Aborigen Americana, donde presenta técnicas curativas indígenas, métodos mágicos, encantamientos, detalla la medicina tupí-guaraní, araucana, incas y aztecas. José Imbelloni (18851967) fue un antropólogo italiano radicado en Argentina que estudió diversas cuestiones de antropología física y americanistica.
}

intervinientes en la configuración del reconocimiento académico de Altieri. De su trayectoria identifico problemáticas, ópticas y mecanismos que fueron definiendo el campo antropológico profesional en el país, particularmente en San Miguel de Tucumán, uno de los más promisorios centros de desarrollo de las ciencias antropológicas del noroeste argentino y una potencial alternativa de acceso de la antropología argentina a la problemática central indoamericana.

\section{Quipus, documentos y academia}

Entre marzo de 1934 y mayo de 1938 Altieri fue ayudante de investigación en el Museo Argentino de Ciencias Naturales Bernardino Rivadavia. En su currículum no figura la forma de ingreso a esta institución ${ }^{3}$. Allí no solo desplegó sus investigaciones sino que además encontró la protección formativa de Imbelloni. Para comienzos de la década de 1930 Imbelloni era una figura relevante dentro del panorama antropológico argentino. Llegó al país proveniente de Italia a principios del siglo XX. Luego participó como voluntario en la Primera Guerra Mundial, y se doctoró en Ciencias Naturales con un trabajo sobre craneometría en la Universidad de Padua (Califano et.al. 1985:41). Se radicó definitivamente en Buenos Aires y comenzó a trabajar en el Museo Argentino de Ciencias Naturales. En este ámbito, entre 1931 y 1946, fue jefe de la Sección de Antropología. Además Imbelloni fue profesor en la Facultad de Filosofía y Letras de la Universidad Nacional de Buenos Aires e investigador desde 1922 del Museo Etnográfico de aquella facultad. Obtuvo la Medalla Holmberg del año 1933, otorgada por la Academia Nacional de Ciencias Exactas, Física y Naturales, por su monografía Los pueblos deformadores de los Andes. Este reconocimiento junto a la publicación de su Epítome de Culturología (1936) y el acceso a la titularidad catedrática, contribuyeron a la fuerza hegemónica teórico-metodológica que Imbelloni mantuvo por lo menos formalmente hasta $1955^{4}$.

En un campo tan reducido, pocas figuras "...eran prácticamente las dueñas de la antropología porteña y representaban para los jóvenes las únicas posibilidades de acceder al sistema académico universitario" (Guber, 2005: 36). Bajo la figura de Imbelloni, una de esas figuras, Altieri se introdujo en una estructura de investigación formal, familiarizándose con las temáticas antropológicas del momento. El 8 de febrero de 1940 Imbelloni certificó el desempeño de Altieri como ayudante anexo a su sección de antropología en el museo Bernardino Rivadavia, y aseguró "... que durante este contacto directo y continuo, el profesor Altieri ha demostrado mucho interés científico, dotes no comunes de observación y una

\footnotetext{
3 Legajo 6467: Radamés Altieri - Archivo Histórico de la Universidad Nacional de Tucumán.

4 Si bien en 1955 Imbelloni es exonerado de la Universidad Nacional de Buenos Aires por haber sido referente académico del peronismo, continuó desempeñándose hasta su muerte como profesor de Antropología y Etnología en la Universidad del Salvador.
} 
capacidad de trabajo realmente rara. No dudo de que su porvenir científico le reserva muchas satisfacciones" 5 .

En forma simultánea al trabajo en el Museo, Altieri se desempeñó como bibliógrafo y traductor en la Revista Geográfica Americana. Desde allí, y utilizando materiales del museo, publicó una serie de artículos (Altieri 1934; 1937 a, b y c; 1938) que lo consagraron como una figura especializada en temáticas andinas. Analizó la importancia del templo de Viracocha en Cancha, y se abocó al desciframiento del sistema de cuerdas con nudos y colores realizados por los incas, los quipus. Hasta 1947 el Museo Bernardino Rivadavia contenía piezas arqueológicas ${ }^{6}$, entre ellas un ejemplar de quipu peruano.

La utilidad de los quipus presentó, ya desde épocas coloniales, una gran diversidad de interpretaciones. En tanto objeto arqueológico, los nudos podrían ser vistos con una funcionalidad contable o numérica. Sin embargo, algunos cronistas, como Felipe Guaman Poman de Ayala (1556-1644), dejaron entrever que los quipus podrían haber servido como una forma rudimentaria o inicial de escritura. Esta última perspectiva inició la posibilidad de ver a los quipus como un documento o fuente secundaria. Allí ancló la construcción de un objeto de estudio interesante para Radamés Altieri, que pudo ser articulado con su especialidad y destrezas para el manejo de cuestiones lingüísticas y documentales. De esta manera Altieri comenzó a participar en el complejo entramado de interpretaciones sobre producciones culturales de tiempos prehispánicos, y pudo con la temática, empezar a ser visibilizado en el ámbito académico.

A su vez esta intervención de Altieri en cuestiones andinas colaboraba con el despliegue académico de su maestro Imbelloni. Precisamente, la propuesta teórica del italiano se venía configurando desde mediados de los '20 con La Esfinge Indiana (1926), publicación que estuvo acompañada por un programa investigativo sobre los orígenes del nuevo americanismo. A mediados de los '30 este programa abrazó la teoría de la Escuela HistóricoCultural, desde la cual intentaba explicar el origen y la naturaleza del hombre americano como trasfondo de la conformación nacional (Figoli 1990). Para Imbelloni el tema central por el que transitaría el americanismo sería el de la disyuntiva entre la dependencia y la convergencia o las creaciones independientes de la cultura americana (Carrizo 2000). Si bien valoraba y buscaba las relaciones interculturales, Imbelloni rechazaba de plano el hiperdifusionismo de la Escuela de Manchester liderada por el anatomista y antropólogo Sir Grafton Elliot Smith (1871-1937).

En la academia argentina el programa imbelloniano

\footnotetext{
${ }^{5}$ Carta de Imbelloni, Buenos Aires 8 febrero 1940. Legajo 6467: Radamés Altieri - Archivo Histórico de la Universidad Nacional de Tucumán.

6 Por Decreto del Poder Ejecutivo el 10 de junio de 1947 se realizó la transferencia de las secciones y colecciones de: Arqueología, Etnografía y Antropología del Bernardino Rivadavia al Museo Etnográfico de la Universidad Nacional de Buenos Aires.
}

presentaba diferencias con la línea del prehistoriador autodidacta Francisco de Aparicio (1892-1951) y del geógrafo humano Romualdo Ardissone (1891-1961), quienes impulsaban la asociación entre la Antropología, la Arqueología y la Geografía Humana o Antropogeografía. La relación entre De Aparicio e Imbelloni es recordada por sus contemporáneos como política y académicamente conflictiva, especialmente desde la exoneración de aquél en 1947 y la posterior asunción en los principales cargos de la antropología porteña por parte de Imbelloni (Guber 2005). El área andina era una preocupación de ambos no sólo por su riqueza intrínseca, sino también porque en su estudio intervenían intelectuales y académicos locales y extranjeros. Quien contribuyera de manera importante al conocimiento de las altas culturas indoamericanas, ganaría un lugar en el concierto mundial de la americanística.

Desde las primeras décadas del siglo XX las academias centrales (Francia, Inglaterra, Alemania y los Estados Unidos) se encontraban definiendo dos paradigmas y objetos de estudio determinados como orientalismo y americanismo. En 1875 la Société Américaine de Francia convocó al Primer Congreso Internacional de Americanistas. A partir de entonces esta actividad científica formó tradición y dio continuidad a los debates en torno a "lo americano". Los investigadores europeos y americanos que querían alcanzar prestigio y reconocimiento debían formar parte, al menos, de las discusiones que en el ámbito de estos congresos se generaban (Ver Zabala, este volumen). El americanismo concentraba su mirada en las llamadas "áreas nucleares" del continente, localizadas en México y Perú, bases de los grandes imperios precolombinos. A principios del siglo XX estos dos países se encontraban en plena conformación de sus estados nacionales, y para ello se valieron de los conocimientos generados por las ciencias antropológicas para establecer un pasado que excediera la llegada del español. En el caso de Perú, Carlos Iván Degregori (1979 y 2000) ha mostrado el aporte de la antropología indigenista al Estado y a la identidad nacional. Sin embargo, en dicha empresa el autor no contempla los aportes decisivos de las prácticas arqueológicas y hasta minimiza el lugar de la arqueología en este proceso, restándole el papel de la materialidad concreta por ella provista, en la conformación de identidades y sus correspondientes patrimonios. Por nuestra parte, entendemos que el exotismo antropológico que propone Degregori nacido del indigenismo, tiene sus raíces en las prácticas arqueológicas de figuras reconocidas en el ámbito internacional, como Max Uhle y Julio Tello, quienes a su vez retomaron los relatos de cronistas y viajeros ${ }^{7}$. Los prolegómenos de las prácticas arqueológicas

\footnotetext{
7 Max Uhle (1856-1944) arqueólogo alemán, especialista en lingüística, y especializado en estudios de las culturas del área andina. Descubrió a la culturas Mochica y Nazca. Estudió profundamente la difusión del quechua y al estado en inca. Difundió sus ideas sobre importaciones culturales a través de la llamada teoría inmigracionista. Julio Tello (1880-1947) médico peruano que se dedicó intensamente a la
} 
allanaron el camino a las propuestas indigenistas, ya que visibilizaron lo indígena a través de los restos materiales precolombinos, denotando así la profunda ancestría y la extensa temporalidad de sus culturas. Durante las primeras décadas del siglo XX, el Perú ingresó a una etapa de afianzamiento nacional, dando lugar a la imagen de una Nación Mestiza en la que se comenzó a asimilar la idea de que lo nacional era un producto nuevo, y que lo indígena era un componente significativo.

Los intelectuales y académicos peruanos propiciaban la integración y generación de un país moderno y racialmente mestizo. Estos actores tuvieron la misión de llevar ese discurso a la ciudadanía. Para esta empresa retomaron los relatos de los viajeros-exploradores y dieron gran participación a escritores, historiadores y arqueólogos. Desde la historiografía se impulsaron profundas ideas sobre el mestizaje, ya que el indio tenía un papel central como protagonista de un pasado relevante. El historiador y antropólogo moqueguano Luis Eduardo Varcalcél (1891-1987) fue uno de los principales difusores de esta propuesta y generador de la corriente indigenista peruana. El presidente Augusto B. Leguía que gobernó en dos ocasiones al Perú-entre 1908/1912 y 1919/1930también promovió el indigenismo creando el Patronato de la Raza Indígena en 1922. Por su parte, el ensayista y político José Carlos Mariátegui (1894-1930) proponía una visibilización del indio sin que éste se viera diluido en aquel mestizaje construido desde el Estado. Lo significativo y relevante de este período fue el "re-descubrimiento del indio", para lo cual era necesario conocer su historia, su cultura y así incorporarlo como parte de la nacionalidad peruana. La cuestión se planteaba cada vez más como parte de la discusión académica.

El noroeste argentino formó parte del despliegue sociocultural andino en el pasado prehispánico, ya que integraba lo que se denominaría luego el área andina meridional. Si bien fue éste un espacio marginal con respecto a las sociedades y organizaciones políticas de las altas culturas del centro del Perú, los indicios de ancestría sobre todo incaica, fueron muy relevantes. El actual territorio de la provincia argentina de Tucumán tuvo una particular contribución en la discusión sobre la extensión territorial y profundidad temporal de las sociedades prehispánicas andinas. Desde la última década del siglo XIX y los primeros años del XX varios investigadores locales y foráneos se abocaron al estudio de las relaciones de las poblaciones que llamaban Diaguitas-Calchaquíes, con la gran influencia cultural del Perú. Esos investigadores comenzaron a plantear distintas posiciones acerca de la originalidad de los patrones culturales del noroeste argentino y su dependencia del imperio incaico. Dos protagonistas de esta polémica fueron el arqueólogo sueco Eric Boman (1868-1924) y el arqueólogo argentino Juan Bautista Ambrosetti (18651917), fundador del Museo Etnográfico de Buenos Aires. Boman creía que los calchaquíes eran una parcialidad de

arqueología de su país los diaguitas y que éstos se encontraban dentro de la gran influencia cultural devenida del Perú prehispánico. En vez, Ambrosetti buscaba saltar la frontera temporal y espacial, ya que para él los calchaquíes eran los habitantes de los valles cercanos a Tafí hasta la Quebrada de Humahuaca, independientes de los incas. El naturalista Carlos Rodolfo Schreiter (1877-1942), miembro de la academia tucumana, contribuyó en la polémica avalando la postura de Boman (Carrizo 2006).

A comienzos de la década de 1940 el debate se amplió y continuó a través de otros actores insertos en linajes académicos (Guber 2005). Existe una clara línea sucesoria entre Ambrosetti, reemplazado tras su muerte por su discípulo y compañero Salvador Debenedetti (18841930) en la dirección del Museo Etnográfico. Al fallecer Debenedetti en 1930, lo sucedió el arqueólogo salteño Félix Outes (1878-1939). Finalmente, tras el retiro de Outes producido en 1937, Fernando de Aparicio llegó a la conducción de dicho Museo. Este linaje no sólo implicaba el pasaje de cargos sino también el de ciertas líneas interpretativas que afloraban en los debates. En los inicios de los años 40', de Aparicio junto a un grupo de alumnos de Historia (pues no existían aún ni Geografía ni Antropología como profesorados, y las licenciaturas se crearían recién en 1956), realizaron varias campañas arqueológicas en el noroeste argentino. Buscaban así congruencias explicativas sobre las cuestiones andinas mediante la combinación entre arqueología y geografía. Pero Imbelloni, también profesor de Historia (cátedra Antropología) en el Museo Etnográfico, buscó con otras estrategias esclarecer el dilema andino. Desde la década de 1920 venía abocado a derribar las especulaciones no científicas, fantásticas e hiperdifusionistas. Al analizar Tiahuanaco, la antigua ciudad preincaica al sureste del lago Titicaca en la actual República de Bolivia, estudió al templo de Kalasasaya y las construcciones megalíticas. En 1942 propuso que "Por lo que concierne al territorio, el Tucumán,..., justo es reconocer que los monolitos de Tafi deben ser interpretados como jalones del limite meridional de difusión andina de esas estructuras" (Imbelloni 1942: 217). Buscaba así insertar las evidencias arqueológicas del noroeste argentino en la dispersión del área andina, y elevar el estatus de la arqueología argentina tratando de hacer ingresar sus planteos en la centralidad de las discusiones sobre lo andino y el americanismo.

En 1938 Radamés Altieri, obedeciendo a la lógica verticalista que encuadraba la relación profesor-discípulo de entonces, ingresó no sólo en la contienda por los espacios académicos sino también en el campo temático en disputa. Ubicado en Tucumán, buscó datos y fuentes de comprobación que pudieran contribuir al estudio de lo andino. Altieri aportó líneas de investigación publicando fuentes históricas, lo cual le sirvió para ser reconocido e incorporado al campo académico. Cuando hablamos de "campo académico" nos referimos a un universo cambiante y también fragmentado, no taxativamente ligado a la política y al Estado. Los cambios institucionales, 
debilitamientos e imposibilidades, definen mecanismos internos propios en la validación de este campo, tal como lo definiera Pierre Bourdieu (1992).

Altieri ingresó formalmente en 1938 como secretario del Instituto de Antropología de la Universidad Nacional de Tucumán. Dicha universidad se creó a principios del siglo XX por iniciativa y con el aval financiero de la poderosa elite azucarera ${ }^{8}$. Pero no era ésta una universidad como sus contrapartes del Plata. Desde sus comienzos ostentó una doble característica: su perfil regional, configurador de una imagen provincial rectora en el contexto del noroeste argentino, y una fuerte orientación técnicoproductiva. La impronta investigativa abocada a resolver necesidades locales en torno a cuestiones de salud pública y de economía regional, terminaba por definir ese perfil.

En la década de 1930 el énfasis tecnológico inicial dio paso a un establecimiento más volcado a la docencia y a las disciplinas sociales y humanísticas. Se conformaron así facultades, institutos y escuelas universitarias. De estas dependencias, los institutos, confluyeron en 1937 en el Departamento de Investigaciones Regionales ${ }^{9}$, cuyo objeto eran las cuestiones de idiosincrasia de la comunidad tucumana y norteña regional. En el foco investigativo no sólo primaba lo técnico sino también el pasado histórico y la identidad cultural. El proyecto de creación de este departamento surgió entre 1929 y 1933, durante el primer mandato rectoral de una figura de primer nivel nacional, el reformista Julio Prebisch ${ }^{10}$. Aunque el proyecto no alcanzó a concretarse sino en su segunda gestión, 1937-1940, Prebisch consolidó su diseño empleando para su ejecución las investigaciones de institutos de diversas ramas y actividades. El Departamento de Investigaciones Regionales fortaleció los recursos humanos de la universidad, generó la producción de material académico presentado en revistas especializadas y en la edición de fuentes inéditas.

El Instituto de Etnología fue incorporado al Departamento de Investigaciones Regionales. Creado en 1928, y hasta 1936, este instituto contó con la dirección del etnólogo suizo Alfred Métraux (1902-1963), discípulo del prestigioso antropólogo Paul Rivet (Bilbao 2002). Luego de su salida, y por el lapso de un año, el antropólogo Enrique Palavecino

\footnotetext{
8 El 4 de noviembre de 1913 comenzó a funcionar su primer Consejo Superior. Este consejo eligió como primer rector a Juan B. Terán el 24 de diciembre de 1913, y la inauguración oficial se produjo el 25 de mayo de 1914.

9 “En 1937 la Universidad organizó el Departamento de Investigaciones Regionales. Lo integraban el Instituto Lillo; el Instituto de Medicina Regional; el Instituto de Historia, Lingüística y Folclore; el Instituto de Antropología; el Instituto de Mineralogía y Geología; el Instituto de Zoología; el Instituto de Investigaciones Técnico-Industriales y el Instituto de Investigaciones Económicas y Sociológicas" (Tagashira 2004)

10 Julio Prebisch (1896-1952) médico que encaró la defensa del movimiento reformista. Fue político y llegó a ser presidente del Consejo Deliberante de la ciudad de San Miguel de Tucumán. A partir de la revuelta estudiantil de 1929 generada por los alumnos del Instituto Técnico Prebisch fue nombrado rector de la UNT, marcó el primer cambio con respecto a los orígenes tradicionales y elitistas de esta universidad.
}

(1900-1966) se hizo cargo de la conducción. Palavecino, cercano al ámbito de Imbelloni, recomendó a Altieri para el cargo de secretario del Instituto de Etnología de Tucumán. El 26 enero de 1938 Altieri escribió una carta desde Buenos Aires al rector Prebisch donde exponía, por consideración de Palavecino, datos que entendía pertinentes sobre su persona. Adjuntaba además un breve currículum donde presentaba sus tareas como ayudante del Museo Argentino de Ciencias Naturales de Buenos Aires, y como traductor de lenguas extranjeras, taquígrafo comercial y perito paleógrafo ${ }^{11}$. También citaba sus artículos de la Revista Geográfica Americana y mencionaba futuras publicaciones e investigaciones.

El 25 de marzo de 1938 Palavecino solicitó a Prebisch la incorporación de Altieri como secretario del Instituto ${ }^{12}$, lo que se efectivizó por resolución del rectorado, el 23 de abril $^{13}$. En mayo, Palavecino renunció para ocupar el cargo de director interino del Departamento de Antropología de la prestigiosa Universidad de La Plata. Por un breve lapso el Instituto de Etnología fue conducido por el entomólogo y arqueólogo alemán Schreiter. El 10 de junio de 1938 Prebisch resolvió crear la "partida de encargado" del Instituto de Antropología, y designar en la máxima posición a Altieri.

La línea regida y creada por Imbelloni ancló en Tucumán, vía Altieri. Este espacio era necesario porque allí estuvieron Métraux y Palavecino, haciendo de él un ámbito relevante y distinto al existente en la academia central porteño-platense. Altieri acuñó una cadena de relaciones que le fueron útiles para ingresar formalmente al ámbito académico antropológico argentino, el cual por entonces se encontraba en plena definición.

Desde mediados de la década de 1930 la antropología y la arqueología practicada en la Argentina, iniciaron una empresa diferenciadora que buscó separar al lenguaje poético-especulativo del discurso científico. Este proceso tuvo varios tramos. Un trayecto representativo se expresó en el conflicto entre la Sociedad Argentina de Antropología (fundada en 1936 por el arqueólogo Outes) y la obra de los hermanos franceses Duncan (1863-1937) y Emilio Wagner (1868-1949). Estos arqueólogos radicados en una localidad del interior de la provincia de Santiago del Estero, sostenían que la región chaco-santiagueña había sido el centro y foco de irradiación de todas las civilizaciones de América y del Viejo Mundo (Wagner y Wagner 1934). Por su parte, los miembros de la Sociedad Argentina de Antropología —José Imbelloni, Eduardo Casanova, Enrique Palavecino, Francisco de Aparicio, entre otros-que operaba primordialmente desde

\footnotetext{
11 Legajo 6467: Radamés Altieri - Archivo Histórico de la Universidad Nacional de Tucumán.

12 El 5 de febrero de 1938 cambió de denominación y pasó a llamarse Instituto de Antropología.

13 Resolución 80/73/938- Archivo Histórico de la Universidad Nacional de Tucumán
} 
Buenos Aires en su Museo Etnográfico, se constituían en parte de la primera entidad específica del campo antropológico nacional tendiente a la profesionalización de la disciplina. Los Wagner fueron expulsados del círculo, pese a que ambos contaban con fluidas relaciones con otras academias nada menores como la francesa, la norteamericana y la italiana (Ocampo 2004).

Francisco de Aparicio, director de la Sociedad Argentina de Antropología desde 1939 luego de la muerte de Outes, coincidió con Imbelloni y los demás miembros de la sociedad en dedicar la Semana de Antropología del año 1939 al estudio de la problemática en torno a los aborígenes de Santiago del Estero ${ }^{14}$. En 1940 la Revista Relaciones, órgano de difusión de la Sociedad, volcó las conclusiones de los trabajos de aquella semana. Cuestiones geográficas, históricas, arqueológicas, antropológicas y paleontológicas del territorio santiagueño aparecieron en una exégesis realizada por los miembros del Consejo Directivo de la sociedad. De Aparicio escribió la Síntesis Arqueológica, desestimando el carácter descriptivo e interpretativo de la obra de los Wagner. Atribuyó este desmérito a la falta de precisión en las condiciones de los hallazgos, "...que solo puede tenerse en cuenta como diagnosis estrictamente científica, la formulada por Frenguelli en el curso de esta Semana, incluida en este mismo volumen" (Aparicio 1940: 75). De esta manera la Sociedad Argentina de Antropología cerró un círculo interpretativo en unos pocos y selectos. Santiago Bilbao analizó en detalle este proceso, y entendió que la descripción de estos hechos y actitudes sirven para "... terminar de caracterizar la práctica del cenáculo que dominó, trabó y se constituyó en supremo juez de lo que debía hacerse y no hacerse en el quehacer antropológico argentino hasta años recientes" (Bilbao 2002: 172). Cuando se creó la Sociedad Argentina de Antropología, en 1936, estuvo "Limitada en un comienzo a los especialistas, en el más estricto sentido del término, debió luego ampliar sus estatutos permitiendo el acceso a todos los que se interesan por los estudios antropológicos. (de Aparicio, 1937:1). A pesar de esto, la Sociedad continuó siendo un círculo cerrado a una red de conocidos, lo cual redundaba en que el Consejo Directivo lo ocupaban las mismas personas que lo habían diseñado. Para el período 1937-1938 ingresaron 36 socios activos y 13 estudiantes, socios honorarios y correspondientes de países extranjeros.

Altieri ingresó a la Sociedad Argentina de Antropología en 1936 junto con los hermanos Wagner, éstos como socios activos y aquél como socio adherente. Sin embargo los Wagner debieron abandonar la Sociedad resultado de la evaluación de la que fueron objeto. El primer estatuto de la entidad contemplaba el ingreso de

\footnotetext{
14 La misma se realizó entre el 26 de junio y el 1 de julio de 1939 Estas semanas eran verdaderos congresos, "... reuniones anuales de especialistas de la ciencia que se llevaban a cabo en distintas ciudades del interior y en la propia capital". (http://www.saantropologia. com.ar/historia.htm)
}

especialistas en tanto "... personas que se dedican a la investigación de alguna de las ramas de la Antropología, como objeto principal de su actividad, y que además de haber producido obras meritorias, han seguido esta actividades con carácter profesional"15. Junto a Altieri se encontraron otras figuras ${ }^{16}$ dedicadas al estudio de temáticas antropológicas. Altieri fue considerado un especialista por los aportes que venía generando en temáticas andinas, y muy probablemente por su mentor y hombre fuerte del círculo, Imbelloni ${ }^{17}$.

Entre 1938 y 1939 tomó posesión en el Instituto de Antropología de Tucumán. Primero lo hizo como secretario y luego como director de aquel instituto. A comienzos de 1939 retomó la empresa editorial iniciada por Métraux en 1929 y diseñó tres líneas de publicación: la Revista del Instituto de Antropología, las Publicaciones Especiales del Instituto de Antropología y las Notas del Instituto de Antropología. El esclarecimiento de cuestiones del panorama lingüístico aborigen se trataba preferentemente en las Publicaciones Especiales del Instituto de Antropología (Carrizo 2010), desde donde editó la obra de Juan de Aguilar Arte de la lengua quichua general de Indios del Perú (1690), y del sacerdote peruano Fernando de la Carrera Daza, Arte de la lengua Yunga (1644). Desde tiempos de la conquista el contacto de lenguas se convirtió en un objeto de estudio. Ahora en Tucumán a través del trabajo de Altieri adquirió gran relevancia, probablemente porque de la lengua se infería la presencia e influencia de otros pueblos, como el debate de los incas en el noroeste argentino. La lingüística ganó un importante terreno en los estudios antropológicos, sobre todo a partir de la década de 1920, con la propuesta de Imbelloni de conformar una nueva americanistica. Esta debía ser, según él, una «ciencia sui generis» (Imbelloni 1926:9) que reposara sobre ciencias tales como Geología, Zoología y Botánica, además de la Lingüística o "Glotología». Imbelloni propició que los estudios lingüísticos dejaran una etapa puramente descriptiva, y pasaran a contribuir en la genealogía de las sociedades americanas prehispánicas. Buscó también

\footnotetext{
${ }^{15}$ Crónica oficial de la Sociedad Argentina de Antropología. Estatuto. Revista Relaciones año 1937.

16 En calidad de socios adherentes de la Sociedad Antropológica Argentina aparecen Romualdo Ardissone (futuro creador de la carrera de Geografía), Julián B. Cáceres Freyre y Adolfo Dembo (quien trabajó con Imbelloni sobre la deformación craneana intencional). Es significativo que entre ellos aparecen varias mujeres dedicadas a la antropología, como la antropóloga física María de las Mercedes Constanzó, Elina González Acha de Correa Morales, Ana Biró de Stern y María Elena Villagra Cobanera. A ellas estaba destinada las tareas de secretaría que en varias oportunidades recayó en María de las Mercedes Constanzó.

17 En la Memoria del período 1937-1938 Altieri ya no figuraba como miembro de la Sociedad Argentina de Antropología. No estoy en condiciones de explicar por qué Radamés Altieri no aparece más en la sociedad, siendo que no existe en su archivo renuncia o noticia de alguna desavenencia con los miembros de la entidad. A pesar de esto, en su trayectoria, el período 1938-1941 es un momento de mayor reconocimiento de Altieri. La correspondencia continúa siendo fluida con los miembros de la sociedad y con pares del exterior, sobre todo con los de Perú.
} 
que la lingüística aportara al correlato entre las razas y los patrimonios materiales.

En cierta medida el trabajo editorial de Altieri en Tucumán aportó a la universidad y a su Departamento de Investigaciones Regionales. No constituyó una superación a la disciplina de la Lingüística, ya que Altieri siguió aplicando la metodología descriptiva y el enfoque eminentemente gramatical. A pesar de ello, las afamadas fuentes documentales del período colonial que Altieri publicó adquirieron un valor científico e histórico-indentitario, sobre todo cuando se relacionó con el avance del americanismo y del indigenismo que primaba por entonces en el Perú. Fue funcional además a la tarea de reconocimiento académico que realizó Altieri, presentándose como especialista en la cuestión.

Articuló el análisis de fuentes documentales con su otro objeto de estudio, los quipus peruanos. Para Altieri documentos y quipus constituían en definitiva un mismo espacio semántico de interpretación y sentido. En 1935 Imbelloni escribió una definición de quipu para la Enciclopedia Italiana ${ }^{18}$, donde le atribuía una función numérica. Por entonces Altieri todavía se encontraba trabajando junto al antropólogo italiano en el Museo Rivadavia. Allí se familiarizó con la temática de los quipus, y en 1937 diseñó un plan para clasificarlos, convirtiéndose en el único referente argentino especializado en la materia. En el artículo El Kipu peruano (1937a) rescataba la importancia de su análisis científico en contraposición a las especulaciones fantásticas. "Como se ve, el problema del Kipu es más complicado que el desciframiento de la escritura egipcia. No hay que desvalorizar por supuesto, los resultados de la ciencia. Conocemos el procedimiento mental que ha producido esta invención de la cultura humana..." (Altieri 1937a:14).

El desciframiento de los quipus era objeto de estudio desde los inicios de la conquista del Tahuantinsuyo. En 1897 el arqueólogo Max Uhle comparó quipus fabricados por los pastores contemporáneos con los datos que proveían las crónicas históricas. Posteriormente otros científicos de prestigio internacional como el sueco Erland Nordenskiöld, el florentino Lidio Cipriani y el norteamericano Leland Locke, analizaron los quipus arqueológicos $^{19}$. A este círculo selecto y de fama académica mundial se sumó Altieri desde 1937. El punto de discusión crucial sobre los quipus se centra, hasta hoy, en su naturaleza mnemotécnica y en la utilidad numérica o alfabético-narrativa. Por ello Urton (2003) entiende que la bibliografía sobre quipus ha procedido en fuertes términos dualistas. Dicho dualismo interpretativo estuvo

\footnotetext{
18 Imbelloni, J. 1935 Quipu. En: Enciclopedia Italiana, vol. XXVIII: 641. Roma.

19 Locke, L. 1923. The ancient Quipu or Peruvian knot-record. Nueva York; Nordenskiöld, E. 1925. The Secret of Peruvian Quipus. Gotemburgo; Cipriani, L 1928. Su due quipus del Museo Nazionale di Antopologia ed Etnologia di Ferenze. Atti del XXII Congresso Internazionale di Americanisti (Roma, 1926). Roma.
}

también presente en los trabajos de Altieri.

En 1939, ya instalado en Tucumán, Altieri retomó sus investigaciones sobre la temática. Utilizando la línea editorial, Notas del Instituto de Antropología publicó su Sobre un quipu peruano (1939). Allí propuso descartar la hipótesis de que el quipu sólo era un objeto de escritura alfabética o silábica, sin tampoco optar por el carácter numérico que había propuesto sobre todo Locke. Altieri afirmaba que los quipus tenían valor convencional, "...y que estas convenciones no son conocidas por nosotros" (Altieri 1939:8). Dos años más tarde en la Revista del Instituto de Antropología, línea editorial de mayor número de ejemplares, Altieri profundizaba su estudio con un trabajo extenso. En Sobre 11 antiguos kipu peruanos (1941) discrepaba con la interpretación numérica, e instaba a abandonar todo intento explicativo en pos de descripciones morfológicas de los ejemplares disponibles. Fotos, cuadros y gráficos acompañaron el complejo ejercicio descriptivo de las piezas. En medio de opiniones, descripciones de cronistas y difusas investigaciones arqueológicas, Altieri cruzó diferentes variables analíticas para contrastar las afirmaciones y observaciones de los primeros relatores con las evidencias que presentaban los quipus conservados en los museos. El material, la direccionalidad de los colgantes, los colores, grosores de los nudos, y las cuerdas subsidiarias, fueron algunos de los elementos que Altieri contempló en su nuevo estudio.

El trabajo con los quipus no solo muestra el rigor científico y los criterios con los que Altieri investigaba, sino que además lo consagró en el campo académico como investigador. Su red de contactos con investigadores e instituciones le permitieron encarar un amplio intercambio bibliográfico y de noticias, y le franquearon el acceso al material arqueológico que era objeto de su indagación. En el artículo Sobre 11 antiguos kipu peruanos analizó piezas nunca antes descriptas, de la colección particular del abogado y docente universitario porteño Luis Molinari (1889-1966).

En el nudo o quipu-de allí el nombre del objeto- Altieri creyó encontrar variaciones técnicas y regionales. Pero por sobre todas las cosas pudo ver una fuente documental comparable a los textos escritos por los primeros cronistas. Así, para Altieri, el nudo de algodón y no el papel, era el principal soporte de los incas. La información contenida tanto en los quipus como en los documentos, relataba para Altieri cuestiones casi contemporáneas, del momento del contacto hispano-indígena.

Por ello era necesario para Altieri obtener la mayor cantidad de fuentes documentales. El 18 de noviembre de 1939 Altieri escribió una carta a Prebisch donde le comunicaba su regreso a las tareas como director tras cumplir una serie de actividades en la Capital Federal. Una había sido la entrega de varias publicaciones del Instituto de Antropología a la casa editorial Coni. Además se había citado con Molinari de quien obtenía en calidad 
de préstamo "... obras rarísimas que el instituto re imprimirá: Descripción del Chaco Gualamba del P. Pedro Lozano y las ediciones latina, alemana e inglesa de la Historia de los Abipones editada en latín en 1783 y cuya primera edición en castellano no sería la de este Instituto. La traducción de este libro valioso estará a cargo del suscripto"20.

El 31 de enero de 1940 se produjo la intervención federal en la Universidad Nacional de Tucumán. El rectorado de Prebisch enfrentó una serie de hechos problemáticos que se agudizaron generando una crisis que culminó con el segundo mandato de su rectorado. A fines de 1939 debió enfrentar un profundo recorte presupuestario, situaciones de violencia en el Consejo Superior y renuncias de docentes presentadas ante el Ministerio de Justicia e Instrucción pública de la Nación. Por el tenor de los acontecimientos el gobierno nacional designó como veedor y posterior interventor de la Universidad de Tucumán a Ismael Casaux Alsina, cuya gestión duró tres meses. Reorganizó a la universidad conforme a los principios de la Ley Avellaneda y dejó de lado al Estatuto Universitario de 1924, sepultando así el influjo reformista. Casaux Alsina convocó a una Asamblea Universitaria para los primeros días de abril de 1940, de la cual fue elegido como rector el abogado y político Adolfo Piossek (1886-1971). Piossek ocupó el cargo hasta 1942 cuando renunció para ser candidato a gobernador por el partido Demócrata Nacional.

La intervención de Casaux Alsina y la administración posterior de Piossek en el rectorado interrumpieron, además, el plan editorial de Altieri quien en 1940 sólo publicó Mataco Grammar del pastor anglicano Richard Hunt. Sin embargo, el prestigio nacional e internacional de Altieri tuvo en este momento un punto culminante. La disposición para apropiarse y mantenerse en una competencia específica que era el dominio de la lingüística aborigen, le valió un gran reconocimiento. Desde el Perú el historiador y antropólogo Luis Valcárcel lo puso en contacto con el quichuista José María Farfán quien le escribió el 22 de enero de 1940: "... Deseo felicitar a usted muy reconocidamente por su esfuerzo americanista de editar libros de investigación glotológica tan necesaria especialmente en el Perú" (Valcárcel, en Tartusi 2000) ${ }^{21}$. En la Argentina, el historiador Enrique de Gandía le manifestaba que "Va usted a continuar la obra de Métraux y, sin duda, a superarla. Hasta pronto, lo saluda con afecto su admirador, amigo y colega..." (de Gandía en Tartusi 2000).

Altieri era reconocido como un par dentro y fuera de la academia. Como director del Instituto de Antropología de Tucumán mantuvo un fluido diálogo y correspondencia

\footnotetext{
20 Legajo 6467: Radamés Altieri - Archivo Histórico de la Universidad Nacional de Tucumán.

21 El trabajo de Marta Tartusi no posee número de página ya que éste es un trabajo manuscrito que ha sido facilitado por Patricia Arenas al autor.
}

con el ámbito antropológico académico, particularmente con los arqueólogos Antonio Serrano (1899-1982) y Eduardo Casanova (1903-1977) y con el antropólogo Milcíades Alejo Vignati (1895-1978). Para la década de 1930 Casanova aportó resultados relevantes al conocimiento arqueológico del noroeste argentino, arremetió al estudio de la cerámica draconiana en Catamarca y retomó el camino de reconstrucción del Pucará de Tilcara en la Puna que había iniciado Salvador Debenedetti luego de la muerte de Ambrosetti. Por su parte Antonio Serrano venía dedicándose notablemente a la arqueología mesopotámica desde la década de 1920. En 1941 se creó el Instituto de Arqueología, Lingüística y Folklore de Córdoba y Serrano fue su primer director. Los estudios osteológicos y de material lítico realizados por Vignati adquirieron gran reconocimiento durante este tiempo.

En 1941 para retomar el plan editorial, Altieri entabló correspondencia con el presidente argentino y fundador de la Academia Nacional de la Historia ${ }^{22}$, el general Agustín P. Justo (1876-1943), solicitándole una serie de documentos sobre indígenas del Chaco y del Tucumán para publicar desde el Instituto de Antropología. En los círculos intelectuales y académicos de aquellos años, la figura de Justo era reconocida por ser poseedor de una valiosa biblioteca en la que predominaban los volúmenes referentes a la historia de América.

También ese año, 1941, Altieri preparó la edición de la obra del sacerdote Florian Pauke Hacía allá y para acá, una entrada a los indios Mocobies, 1749- 1767, que se publicaría en tres volúmenes, el primero en 1942, después de morir Altieri, y los otros dos en 1943. El trabajo de Pauke sacaba a la luz descripciones de los jesuitas en el Río de la Plata. En efecto, en sus palabras iniciales, Altieri ponderaba el acto editorial mismo: "el grupo de jesuitas, que, sin ser cronistas oficiales, $y$ tuvieron la acción propia, en medio de la dura tarea misionera, constituyen un aporte casi infinito, en parte inédito y en parte he visto, para la valoración de esos magníficos esfuerzos historiográficos" (Altieri 1942: XIII). Junto a las revistas del Instituto en tiempos de Métraux, Hacia allá y para acá... fue una de las dos más solicitadas por instituciones nacionales y extranjeras. La otra fue Guía para la investigación etnológica ${ }^{23}$ del antropólogo norteamericano George Peter Murdock (1897-1985). Pero volviendo a la obra del Padre Pauke,

\footnotetext{
22 Desde fines del siglo XIX la Junta de Historia y Numismática fue el órgano de referencia estatal sobre las temáticas vinculadas al pasado histórico nacional. En 1938 la Junta era presidida por el jurista e historiador Ricardo Levene (1885-1959). En conjunción con el gobierno de Agustín P. Justo, Levene decidió elevar al rango de la Junta a Academia Nacional de la Historia.

23 Murdock, George (1939) Guía para la investigación etnológica. Traducción e Introducción por Radamés Altieri. Notas del Instituto de Antropología. Tucumán. Universidad Nacional de Tucumán. Tucumán. Entendemos la intención de editar la Guía adecuándonos a lo que fue la década de 1930 en cuestiones de desarrollo y profesionalización del conocimiento antropológico en la Argentina (Carrizo 2010)
} 
su publicación fue producto de una compleja red de relaciones en la que intervinieron diversos agentes no sólo académicos: la Universidad de Tucumán, desde ya, pero también el Instituto Cultural Argentino-Germano, el Centro Azucarero, el mismo Altieri, el médico Gregorio Aráoz Alfaro (1870-1955), el empresario alemán Ricardo Staudt (1888- 1955) y el abogado y político tucumano Ernesto Padilla (1873-1951). Los recursos económicos e intenciones volcados en su publicación ponen de manifiesto no sólo el reconocimiento de los actores intervinientes, sino también la articulación entre la antropología académica y el complejo productivoindustrial del azúcar con epicentro en esa provincia. La obra tuvo una edición de lujo de veinte volúmenes, y estaba numerada con números romanos. El "I fue para el Presidente de la Nación, Ramón J. Castillo" y el II para su par alemán, "SE der Führer und Reichskanzler Adolf Hitler". Dicho ejemplar fue enviado a la Embajada Alemana en Buenos Aires (Tartusi 2000 y 2008).

El trabajo de Marta Tartusi (2000) concluye con dos interrogantes en torno a la figura de Altieri: su identidad religiosa y su identidad política e ideológica. Para ella, el jesuita e historiador Guillermo Furlong (1889-1974) lo llamaba un joven israelita, aunque la autora lo pone en duda debido a la vinculación de Altieri con la cultura católica y con personajes afines a la política germana del momento, como Staudt y Aráoz Alfaro ligados al Centro Cultural Argentino-Germano. En cuanto a su identidad política e ideológica, Tartusi sospecha de la influencia fascista de Imbelloni en Altieri. La certificación generada por esa autoridad antropológica, que iría in crescendo hasta 1955, habilitó el accionar científico y docente de Altieri, consolidando cierta lógica de linaje. Sin embargo, Altieri avalaba esta pertenencia con el desarrollo de una temática por derecho propio y con productividad interpretativa original.

\section{Clases de Etnografía, Prehistoria y Quipus}

En 1938 Palavecino estaba a cargo de la dirección del Instituto de Etnología y de la cátedra Etnografía y Folklore Argentino en el Departamento de Filosofía y Letras de la Universidad Nacional de Tucumán. Tras pasar a la Universidad de La Plata, el director del departamento que en 1955 sería rector de la Universidad de Buenos Aires, Rizieri Frondizi (1910-1985) solicitó al rector Prebisch el nombramiento de Altieri en el cargo dejado vacante por Palavecino ${ }^{24}$.

El Departamento de Filosofía y Letras había sido creado el 21 de diciembre de 1936 por el Consejo Superior de la Universidad Nacional de Tucumán. Posteriormente el 3 de agosto de 1939 se transformó en Facultad ${ }^{25}$, con

\footnotetext{
24 Legajo 6467: Radamés Altieri - Archivo Histórico de la Universidad Nacional de Tucumán.

25 Resolución 296-80-939 -Expediente 1039-D-939. Archivo Histórico de la Universidad Nacional de Tucumán.
}

el fin de resolver la carencia regional y estructural de profesores con formación pedagógica en el nivel medio. El departamento primero, y luego facultad, ofrecía una carrera conjunta de Historia y Geografía aunque, como en otras academias, la Geografía se consideraba como ciencia auxiliar de la Historia.

Para junio de 1938 y ante lo solicitado por Rizieri Frondizi, el flamante director del Instituto de Antropología, Altieri comenzó a prestar servicios docentes en el Departamento de Filosofía y Letras. El 15 de diciembre del mismo año el Consejo Superior estudió sus antecedentes académicos e investigativos y luego de analizar su trayectoria, el 7 de enero de 1939, por resolución del rector Julio Prebisch, lo designó como profesor de Etnografía y Folklore Argentino ${ }^{26}$. Según el expediente, sus funciones docentes comenzarían a regir desde el $1^{\circ}$ de abril de ese mismo año. En la resolución también se nombraba a Antonio Serrano como profesor de Prehistoria y Arqueología argentina y americana y de Geografía antropológica. Sin embargo, desde el Museo Popular de Paraná Antonio Serrano le escribió a Rizieri el $1^{\circ}$ de marzo excusándose del cargo ofrecido. El 25 de marzo Rizieri dirigió una carta a Prebisch informándole de la renuncia de Serrano y proponiendo en su lugar a Altieri, entendiendo que el Consejo Superior ya había estudiado y aprobado los antecedentes del postulante.

El 15 de mayo de 1939 y sin titulación docente, Altieri fue designado profesor interino en las cátedras de Etnografía y de Prehistoria y Arqueología ${ }^{27}$. Para la primera preparó un programa donde establecía precisiones sobre el concepto de etnografía. Admitía cierta elasticidad en el término debido a la complejidad de los grupos humanos que pertenecían al estudio etnográfico. El problema radicaba en saber qué grupos debían considerarse históricos y cuáles etnográficos. Los históricos, formarían parte del estudio de la historia y los restantes del campo de la etnografía. Así, para Altieri el estudio etnográfico de un pueblo debía llevarse a cabo a través de tres miradores: el somático, referido al estudio racial, de origen y variabilidad, abordado por la antropología física; el lingüístico; y el ergológico, referido al contenido cultural, esto es, a aquellas actividades humanas representadas por las artes, las ciencias, la economía, etc., y al campo animológico que contendría religión, filosofía, magia, forma de gobierno, vida social, etc.

Altieri observaba que los grupos humanos objeto de la ciencia etnográfica habían sido caracterizados por los autores como salvajes y bárbaros, y sugería diferenciar ambos conceptos. Particularizó la etimología de la palabra salvaje, proveniente del latín silva o selva, como habitantes de la selva, de modo que era errado emplear

\footnotetext{
26 Expediente 2978/D/938- Legajo 6467: Radamés Altieri

27 Los análisis vertidos en torno a las temáticas desarrolladas en las clases de Radamés Altieri fueron extraídos de los Apuntes de clases de Etnografía y de Prehistoria del año 1941 - Archivo del Instituto de Arqueología y Museo (IAM) de la Universidad Nacional de Tucumán.
} 
ese término para designar a los primitivos habitantes de las Ilanuras americanas. Así, por ejemplo, en la pampa no había existido selva y por consiguiente el nombre de salvaje no podía corresponder a sus moradores. En suma, Altieri rechazaba por incorrecto el uso de bárbaro o salvaje en etnografía, pero proponía, en vez, el uso del término "primitivo", que debía aplicarse con estricto conocimiento de los pueblos a los que se refería o a los ciclos culturales en que se dividía la humanidad. En un sentido culturalista, Altieri entendió que era correcto hablar de un tipo de civilización o de cultura, en vez de bárbaro o salvaje.

Con respecto a la ubicación de la etnografía en el campo antropológico, Altieri la ubicaba en el cuadro general de las Ciencias del Hombre, en la llamada Antropología General la cual se encargaba del estudio de los grupos humanos. Esta Antropología General comprendía dos ramas: la antropología física que incluía anatomía comparada, craneometría, serología y somatología; y la antropología cultural, con la arqueología, la etnología, la musicología, la sociología primitiva y la etnografía.

Altieri empleaba varias clases para delimitar lo que comprendía por etnografía, una disciplina que analizaba y estudiaba a los pueblos en partes descompuestas. En una segunda instancia la etnografía comparaba culturas y se convertía en Etnología. Altieri precisaba que generalmente los etnógrafos no eran etnólogos. El etnógrafo era quien se dirigía adonde había existido un pueblo, y estudiaba sus vestigios en diversos aspectos de su actividad. Altieri ejemplificaba la tarea del etnólogo con la figura del sacerdote católico de nacionalidad austríaca Wilhelm Schmidt (1868-1954), quien jamás había salido de su escritorio y era, sin embargo, el gran maestro de la Escuela Etnológica Histórico-Cultural, orientación que se impondría en las principales cátedras de Antropología del país y que Imbelloni contribuyó a implantar en Buenos Aires (Fígoli 1990; Guber 2005)

En sus clases Altieri desarrollaba las implicancias de las ciencias auxiliares de la etnografía. La Historia proveía a la etnografía de rastros y vestigios de los pueblos etnográficos. Se animaba a alterar la primacía y el poder hegemónico indiscutible que la Historia tenía hasta entonces. Para Altieri la Etnografía se nutría de la Historia, como sucedía con las crónicas del antiguo Perú que informaban de las costumbres de aquellos pueblos. A su entender la poesía también era una herramienta para reconocer las costumbres humanas. La arqueología, obviamente, era otra de las ciencias auxiliares de la etnografía, a la que Altieri concebía como una etnografía histórica mientras que, en un juego de palabras, la etnografía era una arqueología del presente. Como ejemplo, el descubrimiento arqueológico realizado en 1932 en la provincia de Salta, se develaba una nueva cultura cerámica conocida como Candelaria, que a juicio de Altieri presentaba un instrumental lítico curioso del cual nada decían las crónicas acerca de este pueblo.
La tercera ciencia auxiliar de la etnografía era la antropología entendida, hasta mediados del siglo XIX, como antropología física que abarcaba a la etnografía, etnología y lingüística. Sin embargo, tamaña abarcatividad implicaba para él una exageración. De todos modos y a tono con la época, Altieri señalaba la utilidad de la antropología física para los estudios etnográficos en tanto el estudio de un pueblo involucraba también el de sus caracteres raciales. Además, la antropología física proporcionaba un material necesario para dar cuenta de ciertas costumbres como la deformación craneana, "una moda" que consistía en transformar el cráneo de un niño recién nacido apretándolo con cuerdas o maderas fuertemente atadas a la cabeza para señalar diferenciaciones sociales. Esto era crucial para no asignar los restos craneanos así tratados, a una raza o pueblo diferente. En esta línea se puede observar la influencia y el conocimiento que Altieri poseía de una temática de la que su formador Imbelloni era el mayor referente ${ }^{28}$. El tatuaje también formaba parte de las posibilidades culturales 0 modas, y que debía ser estudiado por la antropología física. Por ejemplo, los chaquenses realizaban una dolorosa operación con espinas en la piel colocando polvo de carbón para imprimir puntos negros que poco a poco tomaban un tinte azulado.

Altieri diseñó doce bolillas para el programa de "Prehistoria"; en las tres primeras desarrollaba generalidades sobre la arqueología y sus diferencias con la prehistoria clásica. Enseñó la teoría de la evolución humana y admitió, con cierta flexibilidad, la cadena biológica en el origen del hombre. "En verdad este problema es más bien de tipo especulativo que de aspecto práctico. Es un problema que escapa a la investigación científica y todo lo que se ha dicho acerca de él, no son más que concepciones hipotéticas y a veces fantásticas. No hay nada extraordinario en colocar al hombre en escala zoológica"29. Para Altieri era necesario analizar los árboles genealógicos y los distintos caminos que había presentado la naturaleza humana hasta llegar a la constitución del homo sapiens sapiens. Al pormenorizar detalles sobre el paleolítico, Altieri destacó el uso necesario de la cronología y de la sistematización de Oswald Menghin (1888-1973), algunos años antes de que el prehistoriador austríaco llegara al Río de la Plata.

En las nueve bolillas restantes Altieri se abocaba a la América prehistórica, en especial al Antiguo Perú. Comenzaba definiendo las cuestiones temporales y diferencias del hombre americano que, por entonces, era la gran temática dentro de la arqueología del continente. También analizaba las fuentes literarias y

\footnotetext{
28 Imbelloni era un especialista en esta temática desde 1920. Y a fines de la década del 30' obtuvo alto renombre un trabajo particular: Dembo, A. e Imbelloni, J. 1938. Deformaciones intencionales del cuerpo humano de carácter étnico. Biblioteca del americanista. Humanior. Buenos Aires.

29 Apuntes de clases de Prehistoria 16/04/1941-Pag 10- Archivo IAM.
} 
arqueológicas peruanas y diferenciaba entre el Perú pre incaico y la situación encontrada por los españoles en el Tahuantinsuyo.

En la bolilla 11 se dedicaba a los quipus. Luego de analizar características, colores, tipos de nudos, etc. se volcaba al arduo problema de su interpretación incluyendo las diferentes apreciaciones que suscitaban en los cronistas. Nuevamente afloraba el dualismo interpretativo. Altieri afirmaba la utilidad contable de los quipus, porque en el antiguo Perú los hombres estaban divididos en clases según la edad y otros datos llevados en los nudos. Confirmaba esta funcionalidad utilizando las noticias transmitidas por los cronistas. Pero también apelaba a interpretaciones modernas, sobre todo la de Locke quien en 1925 inventó un método decimal para interpretar los quipus a través de unidades, decenas y centenas. Sin embargo, para Altieri esta interpretación no incluía las cuerdas dobles, por lo que Altieri valoraba la propuesta de Locke en sus términos teóricos más que en su aplicación práctica. Lo mismo sucedía con el etnógrafo Erland Nordenskiöld cuya interpretación astronómica de los quipus era difícil de aceptar.

Altieri buscó correlaciones de los quipus con otros objetos portadores de algún mensaje, como los de la Isla de Pascua, con signos indescifrables. En esta interpretación siguió a Imbelloni quien demostraba que con esos signos convencionales se podían repetir historias, genealogías, cantos, etc. Además Altieri dejó intuir la utilidad religiosa de los quipus, comparándolos con los rosarios utilizados en las misas católicas. Para avalar esta idea volvía a los cronistas; para el padre Lozano los quipus servían para recordar "hechos" cuando los indios se iban a confesar; solían usar un quipu para recordar sus pecados.

Altieri diferenciaba entre los quipus antiguos y los modernos; éstos, utilizados como elemento contable, no servían para entender el sentido de los quipus antiguos.

La difusión del quipu sugería que habían sido empleados en todo el mundo: el Tíbet, Rusia siberiana, África, etc. Citando a Herodoto, sostenía que en la Grecia antigua, los persas emplearon cuerdas con nudos que iban desatando a medida que transcurrían los 60 días en que atravesaron el Helesponto. La difusión del quipu tenía, para Altieri, un sentido universal. "En cuanto al origen del quipu americano, el doctor Paul Rivet establece que vinieron de Oceanía, cosa que nos parece muy bien $»^{30}$.

En sus clases Altieri reiteraba la idea de la multiplicidad y variabilidad de los quipus. Basándose en las interpretaciones del padre jesuita Bernabé Cobo (15801657) quien estudiara los quipus de Ica, sostenía que los mensajes de una región eran indescifrables en otras, lo cual le confería, según Altieri, una adscripción regional a la confección, uso y decodificación de los quipus. Para

\footnotetext{
30 Apuntes de clases de Prehistoria- Archivo IAM.
}

ello explicaba la funcionalidad de los quipucamayoc, burócratas del imperio incaico y encargados de su confección e interpretación. Para Altieri había quipucamayoc de censos, de productos, y quipucamayoc crono-históricos.

En suma, Altieri no sólo revisaba escritos de otros autores acerca de estos objetos indoamericanos; también profería interpretaciones, sugería lecturas y diseñaba líneas futuras de investigación antropológica transamericana referidas a la América nuclear.

\section{Reflexiones finales}

Al vincularse con Imbelloni en el Museo de Ciencias Naturales de Buenos Aires, Altieri adquirió una formación específica que facilitó su ingreso a un círculo profesional, como la Sociedad Argentina de Antropología. Sin embargo, el ámbito académico porteño-platense disponía de muy pocos puestos para demasiados interesados. Tucumán fue una alternativa promisoria. El prestigio de esta vieja y significativa provincia, el aporte de personajes políticos y culturales de la élite azucarera, y la referencia en cuestiones de americanismo, fueron motivos más que suficientes para que Altieri buscara allí su inserción institucional, inserción que contó con la referencia de su maestro, pero también del director saliente Palavecino. Una vez instalado en esta provincia, recorrió un camino muy exitoso con plenas contribuciones que lo visibilizaron en un campo complejo que afrontaba por entonces un decidido proceso de profesionalización.

La falta de titulación no le impidió ejercer la docencia en una universidad que se encontraba en crecimiento y ampliación de sus recursos humanos. Desde la cátedra, Altieri podría haber sido considerado un "mero históricocultural", pero no renegó de cierto evolucionismo ni minimizó la importancia de la etnografía. Radamés Altieri falleció repentinamente encontrándose de viaje en Buenos Aires a los 39 años, dejando un lugar vacante en la red académica que Imbelloni intentó construir en la década de 1930. Entre sus documentos figura su colaboración en una obra que Imbelloni publicaría en 1946, Pachacuti IX. El incario critico, además de varios trabajos inconclusos e inéditos, como el Examen histórico-cultural del viaje de Pedro Cieza de León, en sintonía con la escuela que abrazara su maestro Imbelloni.

Es cierto que la breve pero intensa trayectoria académica de Altieri tuvo el reconocimiento de sus pares por integrar un programa de alcance nacional, pero también por mérito propio. Pese a que nuestro autor no se definió en el dualismo entre "empleo numérico" y "función narrativa" de los quipus, postergando el desciframiento del enigma de los quipus antiguos hasta la aparición de una "nueva Roseta". Supo articular en forma simultánea dos objetos de estudio, documentos y quipus, y por ello tendió a acercarse a la funcionalidad narrativa de los 
quipus, adelantándose en tres décadas a las elaboraciones últimas de los expertos en el hemisferio norte.

San Miguel de Tucumán, 22 de agosto de 2010.

\section{Bibliografía}

Altieri, R.1934. El templo de Viracocha en Cacha. Revista Geográfica Americana, n¹4, noviembre. Buenos Aires.

Altieri, R.1937a. El Kipu peruano. Revista Geográfica Americana, $\mathrm{n}^{\circ}$ 40, enero. Buenos Aires

Altieri, R.1937 b. El camino de Collasuyu. Revista Geográfica Americana, n 45, junio. Buenos Aires

Altieri, R. 1937 c. Los estudios geográficos y la cartografía del siglo XVII. Revista Geográfica Americana, n 47, agosto. Buenos Aires

Altieri, R.1938.Los indios Yámana de Tierra del Fuego. Revista Geográfica Americana, n 55, abril. Buenos Aires.

Altieri, R.1939. Sobre un quipu peruano. Notas del Instituto de Antropología, tomo I, nº 1, Tucumán.

Altieri, R.1941. Sobre 11 antiguos kipu peruanos. Revista del Instituto de Antropología, vol 2, nº 8, Tucumán.

Bilbao, S. 2002. Alfred Métraux en la Argentina. Caracas, Editorial Comala.com.

Bourdieu, P. y Wacquant, L. 1992. An invitation to reflexive Sociology. The University of Chicago Press.

Califano, M.; Pérez Diez, A. y Balzano, S. 1985. Evolución de las ciencias en la República Argentina. 1872-1972. Antropología. Centro Argentino de Etnología Americana (CAEA). En: Sociedad Científica Argentina. Tomo X.

Carrizo, S. 2000. José Imbelloni (1885-1967): entre la Antropología y la Historia. Un aporte para la construcción de la historiografía antropológica argentina. Tesis de Licenciatura. Facultad de Filosofía y Letras. Universidad Nacional de Tucumán (inédita).

Carrizo, S. 2006. Carlos Rodolfo Schreiter: generador de la tarea arqueológica en la provincia de Tucumán. En: Actas de las VI Jornadas: La Generación del Centenario y su proyección en el Noroeste Argentino (1900-1950). Fundación Miguel Lillo - Centro Cultural Alberto Rougés. Tucumán.

Carrizo, S. 2010. Miradas reflexivas en torno a las publicaciones del Instituto. En: Aschero, C, Arenas, P. y Taboada, C. Rastros en el camino... Trayectos e identidades de una Institución. EDUNT. (En prensa) de Aparicio, F. 1937. Prefacio. En: Revista Relaciones de la Sociedad Argentina de Antropología. Tomo I. Buenos Aires.

de Aparicio, F. 1940. Síntesis arqueológica. En: Revista Relaciones de la Sociedad Argentina de Antropología. Tomo II. Buenos Aires.

Degregori, C. 1979. Indigenismo, clases sociales y problema nacional. Ediciones Celats. Lima.

Degregori, C. 2000. Panorama de la antropología en el Perú. Del estudio del Otro a la construcción de un nosotros plural. En: Degregori, Carlos I (edit.): No hay país más diverso. Compendio de antropología peruana. IEP. Lima.

Fígoli, L. 1990. A ciencia sob olhar etnográfico. Estudo da Antropología Argentina. Brasilia, Tesis doctoral, Universidade de Brasilia.

Imbelloni, J. 1942. Kalasasaya. En Relaciones de la Sociedad Argentina de Antropología, n³:189-217.

Guber, R. 2005. Linajes ocultos en los orígenes de la antropología social de Buenos Aires. En: Avá Revista de Antropología, diciembre 8:26-56.

Neiburg, F. y Plotkin, M. 2004. Intelectuales y expertos. La construcción del conocimiento social en la Argentina. Paidós. Buenos Aires.

Ocampo, B. 2004. La nación interior. Canal Feijóo, Di Lullo y los hermanos Wagner. El discurso culturalista de estos intelectuales en la provincia de Santiago del estero. Editorial Antropofagia. Buenos Aires.

Tagashira, R. 2004. La Investigación Científica en La Universidad Nacional de Tucumán. Desde La Fundación Hasta 1966 Antecedentes, Políticas y Relevamiento. Eje Temático: Investigación, Ciencia y Transferencia

Tartusi, M. 2000. La Antropología en Tucumán (19381942): Radamés Altieri. Ponencia del Simposio Historia de la Antropología Argentina. Mar del Plata (mimeo).

Tartusi, M. 2008. La Antropología en Tucumán entre 1930 y 1970: ¿Proyecto político, proyecto institucional o proyecto disciplinar? Tesis de Maestría en Gestión de la educación Superior. Universidad Nacional de Santiago del Estero (mimeo).

Urton, G. 2003. Signs of the Inka Khipu Binary Coding in the Andean Knotted-String Records. University of Texas Press.

Wagner, E. y Wagner, D. 1934. La civilización Chaco Santiagueña y sus correlaciones con las del Viejo y Nuevo mundo. Ed Cía Impresora. Buenos Aires. 